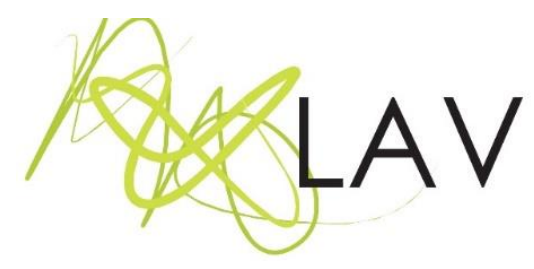

\title{
Musicalização: memórias, experiências e sensibilidades na terceira idade
}

Musicalization: memories, experiences and sensibilities in the third age

Musicalización: memorias, experiencia y sensibilidad en la tercera edad

\author{
Hilda Natume \\ Universidade da Região de Joinville \\ Silvia Sell Duarte Pillottoii \\ Universidade da Região de Joinville
}

Mirtes Antunes Locatelli Strapazzoniii

Belas Artes Joinville

\begin{abstract}
Resumo
Este artigo, recorte de uma pesquisa acadêmica, teve como objetivo analisar as práticas educativas em musicalização na terceira idade, mobilizando memórias e experiências como construção de sentidos e relações com o cotidiano. Para concretização da pesquisa desenvolvemos experiências com um grupo de 30 idosos num Centro de Referência de Assistência Social e num Centro de Artes, oportunizando-Ihes revisitarem memórias a partir de práticas educativas em musicalização, bem como apreciação musical. A pesquisa, de abordagem cartográfica, pautou-se nas narrativas e experiências dos idosos por meio de práticas educativas em musicalização, buscando potencializar esses dois espaços e valorizar as suas ações cotidianas. Os resultados apontaram que a musicalização reativou a memória dos idosos por intermédio de vivências das músicas e letras de outras épocas de suas vidas, mobilizando-os a valorizar o ontem como essencial no seu dia a dia. Fazer e apreciar música oportunizou o compartilhamento de ideias e sentires.
\end{abstract}

Palavras-chave: Práticas educativas, Terceira idade, Musicalização, Memória, Experiência.

\begin{abstract}
This article, cut out of an academic research, aimed to analyze the educational practices in teaching music in the third age, mobilizing memories and experiences as a construction of meanings and relations with the quotidian. For the realization of the research we developed experiences with a group of 30 elderly people in a Social Assistance Reference Center and a Center for the Arts, enabling people to revisit memories from educational practices in musicalization as well as music appreciation. The research of cartographic approach was based on the elderlies' narratives and experiences through educational practices in musicalization, seeking to strengthen these two spaces and enhance their everyday actions. The results showed that the
\end{abstract}

Revista Digital do LAV - Santa Maria - vol. 11, n. 1, p. 211 -234 - jan./abr. 2018 ISSN 1983 - 7348 http://dx.doi.org/10.5902/1983734830932 
musicalization reactivated the elderlies' memories through the experiencing of songs and lyrics of previous times in their lives, mobilizing them to value the past as essential in their daily lives. Making and enjoying music allowed them to share ideas and feelings.

Keywords: Educational practices, Third age, Music, Memory, Experience.

\section{Introdução}

O artigo aqui apresentado faz um breve recorte de uma pesquisa acadêmica, que teve como protagonistas 30 idosos que frequentam um Centro de Referência de Assistência Social (CRAS). Durante o processo da pesquisa os idosos narraram suas experiências sensíveis e afetivas, mobilizados pelas práticas educativas em musicalização.

Este artigo divide-se nos seguintes itens: A cartografia como abordagem de pesquisa; Conhecendo os conceitos: idoso, velhice e terceira idade; Musicalizando idosos; Movidos pelas sensibilidades, memórias e experiências; O campo de pesquisa - uma experiência singular; Visita/expedição ao Centro de Artes; Práticas educativas em musicalização - oficinas no CRAS, além das últimas considerações.

No primeiro item, a cartografia tem como premissa tecer os fios entre as práticas educativas em musicalização e as narrativas e a experiência dos idosos, em caminhos que envolveram também nossos próprios ensaios como pesquisadoras. No item seguinte, apresentamos o conceito de idoso, velhice e terceira idade, pautado na esfera social e contemporânea, pois entendemos que os idosos têm possibilidades e potencialidades outras, uma vez que essa etapa de vida ainda continua pulsando num ritmo ativo. A seguir destacamos a musicalização como possibilidade de revisitamento da memória e relações da vida passada e presente. Um compasso que ressignifica a vida vivida com a vida presente, produzindo novos sentidos. O que nos leva ao item seguinte, trazendo a sensibilidade, a memória e a experiência como fios condutores para o sentido da vida cotidiana. O campo de pesquisa, como experiência singular, a visita/expedição num Centro de Artes e as práticas educativas em musicalização vêm como itens seguintes, ouvindo os protagonistas da pesquisa, em articulação com os conceitos por nós estudados e vivenciados. Por último, nossas breves considerações, em que mapeamos alguns efeitos e sentidos constituídos nesta pesquisa pelos idosos e por nós, pesquisadoras.

Revista Digital do LAV - Santa Maria - vol. 11, n. 1, p. 211 -234 - jan./abr. 2018 ISSN 1983 - 7348 http://dx.doi.org/10.5902/1983734830932 


\section{A cartografia como abordagem de pesquisa}

A abordagem cartográfica, método escolhido por nós, teve como princípio o acompanhamento de processos, conexão em redes ou rizomas. Gilles Deleuze e Félix Guattari foram os precursores do que sugere o pensamento rizomático, que trata de investigar um processo de produção subjetiva.

Nesse contexto, Kastrup e Barros (2014, p. 79) dizem que "a pesquisa cartográfica consiste no acompanhamento de processos, e não na representação de objetos". Não há o isolamento do objeto de seu meio cultural, o acontecer se dá em campo. $O$ pesquisador, nessa abordagem, vai ao encontro - aberto, mergulhando totalmente na pesquisa/experiência. Há então uma maneira de se aprender, ou seja, praticando a cartografia, e não a aplicando (PASSOS; KASTRUP; ESCÓSSIA, 2014).

A cartografia encontra-se como método de intervenção e produção subjetiva, científica e, ao mesmo tempo, sensível. Porém, ao contrário do que se pensa, cartografar exige rigor na caminhada, na precisão e em todos os movimentos da pesquisa/vida. "A precisão não é tomada como exatidão, mas como compromisso e interesse, com implicação na realidade, como intervenção" (PASSOS; KASTRUP; ESCÓSSIA, 2014, p. 11).

Tramando ou tecendo, as linhas na dimensão da cartografia não se apresentam como as linhas da pauta, linear e horizontal, e sim, como uma partitura ${ }^{1}$ musical, as linhas da pauta são atravessadas pelos travessões verticais formando os compassos verticais, que seguem com traçados pelas ligaduras e pontos de um lado a outro das notas musicais. Assim, cartografia como método de pesquisa é sim um "acompanhamento do traçado desse plano ou linhas que o compõem. A tecedura não se faz de maneira só vertical e horizontal, mas também transversalmente" (PASSOS; BARROS, 2014, p. 28). As regras de pesquisa são entendidas como pistas, como já ditas anteriormente, as quais têm a função de "[...] nos guiar no trabalho da pesquisa, sabendo que para acompanhar processos não podemos ter predeterminado de antemão a totalidade dos procedimentos metodológicos" (PASSOS; KASTRUP; ESCÓSSIA, 2014, p. 13).

\footnotetext{
${ }^{1}$ Partitura musical - forma de música escrita ou impressa em que pentagramas são normalmente ligados por barras de compasso a linhas na vertical, de maneira a representar visualmente a coordenação musical (DICIONÁRIO, 1994, p. 702).
}

Revista Digital do LAV - Santa Maria - vol. 11, n. 1, p. 211 -234 - jan./abr. 2018 ISSN 1983 - 7348 http://dx.doi.org/10.5902/1983734830932 
Quanto à formação do pesquisador/cartógrafo, não está embasada na experiência passada, e sim no presente. Envolve postura, disponibilidade, atitude, uma posição em relação ao mundo e a si mesmo. Para ser cartógrafo é necessário mais que ler livros sobre o tema pesquisado. É preciso sair a campo, seguir processos, habitar um território, deslocar a atenção, experimentar, praticar a escrita considerando a produção coletiva dos saberes. Tendo ainda em vista que pode ocorrer o inesperado, o imprevisível (PASSOS; KASTRUP; ESCÓSSIA, 2014).

Desse modo, nossa busca a campo envolveu atitude, disponibilidade de trabalhar com os processos nos territórios propostos, entre tantas outras práticas, mas em primeiro andamento foi conhecer os conceitos que abordam tal pesquisa.

\section{Conhecendo os conceitos: idoso, velhice e terceira idade}

Para alcançar outros territórios, espaços e lugares com outras histórias, caminhos e movimentos, o conceito de idoso, velhice e terceira idade foi essencial nos movimentos de pesquisa.

Quando pensamos sobre idoso, geralmente vimos a imagem de um sujeito que pertence a uma etapa de vida com maior maturidade, que normalmente se encontra acima de 60 anos de idade, com experiências sentidas e vividas no decorrer do tempo cronológico. O idoso é considerado o sujeito do envelhecimento com seu corpo sofrendo alterações nessas passagens.

Notamos muitas vezes que na vida social há o fator da marginalização do idoso. Também ocorre o declínio de suas características físicas, como as rugas, os cabelos brancos, a diminuição da memória, e alterações psíquicas, como a perda da confiança, o aumento da angústia e, muitas vezes, a vinda da depressão (AZAMBUJA, 1995 apud LUZ, 2008).

No entanto, nas relações que estabelece com seus pares, com os espaços, com a família, enfim, com as suas atividades sociais, o idoso pode constituir situações de interatividade e construir identidades. Para Mercadante (2003 apud LUZ, 2008, p. 35),

[...] o conhecimento da existência de um modelo social amplo e geral de velho presente no imaginário social, que se constrói pela contraposição à identidade de jovem, levou-nos a pensar sobre questões relativas à construção da identidade do idoso

Revista Digital do LAV - Santa Maria - vol. 11, n. 1, p. 211 -234 - jan./abr. 2018 ISSN 1983 - 7348 http://dx.doi.org/10.5902/1983734830932 
e de como esta mesma identidade é sentida e vivida por aqueles indivíduos classificados como velhos.

Existem ainda as singularidades do idoso, como envelhecimento corporal, algumas limitações físicas e às vezes cognitivas, e tantas outras, variando sempre de idoso para idoso. No entanto vale destacar que os idosos são participantes ativos dos processos culturais como sujeitos sociais, independentemente de seu estado físico e/ou cognitivo.

Nessa perspectiva, o que pode representar a palavra velho para a sociedade? Refletimos a respeito de tal conceito, lembrando das palavras de Bosi (1979, p. 23), quando diz: "Ser velho é lutar para continuar sendo homem".

Ser idoso na sociedade capitalista é sobreviver. Esse sujeito, muitas vezes sem projeto, fica impedido de lembrar ou de ensinar, suportando as adversidades de um corpo que envelhece, perdendo movimentos "à medida que a memória vai-se tornando cada vez mais viva, a Terceira Idade, que não existe para si, mas para o outro" (BOSI, 1979, p. 23).

Assim, entramos na terceira idade. Esse tempo muitas vezes se encontra localizado entre a aposentadoria e o envelhecimento, também é considerado apenas uma categoria social e que possui um estatuto próprio há pouco tempo.

Uma das concepções desse momento de vida - terceira idade - em nossa sociedade conduz a um pensamento de improdutividade de final de vida. Entretanto é o tempo em que os idosos podem desfrutar um envelhecer produtivo, autônomo e constitutivo de maturidade, com reconhecimento como cidadãos partícipes da sociedade (LUZ, 2008).

Pensamos nas características do idoso na terceira idade como o (entre) laçamento de muitas linhas: de relações, de meios, de idades, de momentos de vida, de experiências e de subjetividades como dispositivos. Lembrando das palavras de Deleuze e Guattari (1990 apud KASTRUP; BARROS, 2014, p. 78), "a linha de subjetivação é um processo, uma produção de subjetividade, num dispositivo: ela deve se fazer, para que o dispositivo a deixe ou a torne possível...".

Revista Digital do LAV - Santa Maria - vol. 11, n. 1, p. 211 -234 - jan./abr. 2018 ISSN 1983 - 7348 http://dx.doi.org/10.5902/1983734830932 
Nesse contexto e na dimensão cartográfica, ressaltamos que optamos em usar os termos idosos como sujeitos e terceira idade como a etapa de vida destes, porque assim entendemos esse tempo/etapa de vida.

\section{Musicalizando idosos}

Neste item apontamos a concepção de musicalização como uma proposta que pode revelar uma visão de mundo. Trazemos, então, Souza (2008, p. 146), ao refletir sobre a música como construção humana, perguntando "[...] é na natureza social e pessoal das relações que o ser humano estabelece com a música que se elaboram significados e que uma sociabilidade se constrói pela e com a música? ". Tal indagação talvez possa estar em nossa mente há algum tempo e, quando escrevemos sobre o assunto, retornamos ao conceito de musicalização como um processo, ou uma atitude ou uma ação de musicalizar, ou seja, de sensibilizar as pessoas. Nesse contexto, o idoso por meio da música pode reagir e movimentar-se com ela (GAINZA, 1998 apud PENNA, 2015).

No processo de musicalização os idosos foram afetados pelos sons, pelos fenômenos sonoros e pelas músicas durante as práticas educativas em musicalização. Suas memórias foram despertadas, potencializando processos de sensibilidades.

A música está intrinsecamente inserida nas manifestações do cotidiano do ser humano e em espaços múltiplos: na rua, em casa, na escola, no museu, no teatro, entre outros. Com os idosos não é diferente; a música está onde eles também se encontram, porém nem sempre a percebem de forma a ampliar seus processos de socialização.

Gainza (1998 apud PENNA, 2015, p. 30) compreende que o "[...] musicalizar (-se): tornar (-se) sensível à música" possa mobilizar os idosos a seguir reagindo e movendo-se com a música, possibilitando-Ihes viver seu tempo de vida em seu território existencial.

O "musicalizar-se" está associado a "estar sensível à música", compreender a música por meio de percepção auditiva com um padrão cultural compartilhado, experienciado no cotidiano, não esquecendo que também pode ser aprendido na escola. "Musicalizar é desenvolver os instrumentos de percepção necessários para que o indivíduo possa ser sensível à música, apreendê-la, recebendo material sonoro/musical como significativo" (PENNA, 2015, p. 31).

Revista Digital do LAV - Santa Maria - vol. 11, n. 1, p. 211 -234 - jan./abr. 2018 ISSN 1983 - 7348 http://dx.doi.org/10.5902/1983734830932 
A escolha, portanto, em musicalizar idosos perpassa pela dimensão de desenvolver ou aprimorar os esquemas de apreensão da linguagem musical, promovendo experiências artístico-culturais e proporcionando a familiarização de distintas formas da linguagem musical, de modo a interligar os processos de propagação da sua cultura em seu ambiente. Sobre essa questão, Penna (2015, p. 44) diz:

[...] a musicalização não se exaure em si mesma. Ela articulase à inserção do indivíduo em seu meio sociocultural, devendo, portanto, contribuir para tornar a sua relação com o ambiente mais significativa e participante.

Dessa forma, os idosos foram movidos pelo prazer estético, atravessando horizontes sensíveis, criativos no ativar de suas memórias e experiências, relacionando-as com o movimento da mediação por meio da musicalização. Contribuiu ainda, nas ações de socialização, uma vez que possibilitou experiências em que os sentidos, as relações afetivas e as memórias dos idosos foram ativadas. Trouxe ainda, a vínculos afetivos entre os idosos sujeitos da pesquisa e entre nós cartógrafos/pesquisadores. A arte pode ser explorada pelo viés da sensibilidade, aqui em específico nas práticas educativas em musicalização. Outras experiências sensíveis aconteceram quando os idosos revisitaram suas memórias e conversas com o passado, ocasionando memórias múltiplas. Algumas das memórias sem sequência lógica e outras com histórias incríveis, avivando ao presente significados com sentidos. A mediação pela musicalização possibilitou saberes e colaborou na desconstrução de alguns conceitos, como por exemplo, que o idoso já aprendeu tudo durante sua vida ou que não pode mais viver com prazer; ou seja, permitiu a construção de outros sentidos ao tempo da terceira idade.

A educação pelo olhar sensível no contexto da terceira idade requer mobilizar memórias e experiências dos idosos como possibilidade de construção de sentidos e relações com o seu cotidiano. Para o idoso é vital ter uma vida prazerosa, desenvolvendo suas potencialidades, a fim de socializar-se com outros e seu entorno. Nisso consistem a mediação cultural e a musicalização.

\section{Movidos pelas sensibilidades, memórias e experiências}

A sensibilidade pode ser promotora de outros conhecimentos em nosso cotidiano e é inerente à vida humana (DUARTE JR., 2010). Então, partindo do cotidiano do idoso, das suas subjetividades e dos seus afetamentos, esta pesquisa trouxe desafios a eles, desenvolvendo práticas educativas em musicalização, tendo a afetividade, a memória e a ação mediadora sensível como balizadoras desse processo.

Revista Digital do LAV - Santa Maria - vol. 11, n. 1, p. 211 -234 - jan./abr. 2018 ISSN 1983 - 7348 http://dx.doi.org/10.5902/1983734830932 
E por falar em memória, podemos dizer que, enquanto escrevemos este texto, buscamos também nossas próprias memórias, nossos afetos e as experiências vividas nos momentos das oficinas no Centro de Referência de Assistência Social $\left(\right.$ CRAS $\left.^{2}\right)$ e da visita/expedição a um Centro de Artes. E assim vamos conectando afetos, indo e vindo nessas linhas da cartografia como se fossem as linhas da clave de $\mathrm{sol}^{3}$ ( termo este usado como uma figura de linguagem, conectando a música com o processo de pesquisa) sobre a pauta ${ }^{4}$ musical.

É fundamental ativar o potencial de ser afetado, de afetar-se, como foi na experiência da visita/expedição ao Conservatório Belas Artes de Joinville, um Centro de Artes, em que realmente fomos afetadas com a surpresa e o deslumbramento daqueles idosos quando chegaram ao espaço cultural e, mais ainda, quando assistiram ao espetáculo de música, especialmente preparado para eles.

Posteriormente ao espetáculo, fizemos uma roda de conversa com os idosos, que na ocasião recordaram passagens de suas vidas, narrando suas histórias, com um misto de frustrações, saudade e alegrias despertadas pela música. Como asseguram Deleuze e Guattari (2010, p. 193-194):

Os perceptos não mais são percepções, são independentes do estado daqueles que o experimentam; os afectos não são mais sentimentos ou afecções, transbordam a força daqueles que são atravessados por eles. As sensações, perceptos e afectos, são seres que valem por si mesmos e excedem qualquer vivido.

Trazemos como pauta nesse processo a educação pelo olhar sensível como promotora de vínculos afetivos e podemos dizer que, como professoras, buscamos ser provocadoras de afetos, sempre afetadas com algo que volta para nós, num vai e vem, num devir! "O afeto [...] é um mapa sensível do que acontece em aula, como o que chega e sai dela, transmutado em valor para a vida pessoal e social" (MEIRA; PILLOTTO, 2010, p. 11). A escuta é fundamental também no processo de mediação. É sentido da coexistência e do significado. E como nos relata Granja (2006, p. 65)

\footnotetext{
2 Os CRAS são unidades descentralizadas da política de assistência social responsáveis pela organização e oferta de serviços de proteção social básica do Sistema Único de Assistência Social (SUAS) nas áreas de vulnerabilidade e risco social. Nos CRAS operam o serviço de Proteção de Atenção Integral à Família (PAIF) e o Serviço de Convivência e Fortalecimento de Vínculos (SCFV) (CRAS, 2017).

${ }^{3}$ Clave de sol é um símbolo que indica a altura das notas na partitura, ou seja, a pauta ou pentagrama é uma disposição de cinco linhas e quatro espaços onde são escritas as notas musicais e outras notações, como claves, fórmula de compasso. É a clave que dá o nome da nota e a figura musical que a representa. ${ }^{4}$ Pauta é um conjunto de linhas em que, nos interstícios, sobre, acima e abaixo delas, se escrevem notas musicais. A disposição de cinco linhas e quatro espaços é a mais utilizada; além das notas musicais, outras notações, como claves, fórmula de compasso, andamentos, também são escritas (DICIONÁRIO, 1994, p. 707).
}

Revista Digital do LAV - Santa Maria - vol. 11, n. 1, p. 211 -234 - jan./abr. 2018 ISSN 1983 - 7348 http://dx.doi.org/10.5902/1983734830932 
"nos permite ter acesso à palavra falada e, com isso, ao mundo das outras pessoas e do conhecimento". A escuta, por meio do olhar sensível nos invade com o interesse, a atenção, o afeto e a motivação e, dessa maneira, selecionamos o mundo sonoro que nos toca e mobiliza com uma atitude a mais do que a exposição de ouvir os sons musicais ou outros.

A terceira idade é uma etapa existencial benéfica aos idosos, com possibilidades de renovações e mudanças a partir de experiências sensíveis. A arte pode ser explorada pelo viés da sensibilidade, aqui em específico na prática educativa em musicalização (LUZ, 2008).

O idoso, ao revisitar suas memórias, conversa com o passado, trazendo lembranças múltiplas, algumas sem sequência lógica e outras com histórias incríveis e divertidas, avivando ao presente significados com sentidos. E como questiona Bosi (1979, p. 47), qual seria então a função da memória?

Não reconstrói o tempo, não o anula tampouco. A anamnesis (reminiscência) é uma espécie de iniciação como a revelação de um mistério. A visão dos tempos antigos libera-o de certa forma, dos males de hoje. Hoje a função da memória é o conhecimento do passado que se organiza, ordena o tempo, localiza cronologicamente. Entre o ouvinte e o narrador nasce uma relação baseada no interesse comum em conservar o narrado que deve poder ser reproduzida.

O narrador conta o que ele apreende da experiência - sua própria ou aquela contada por outros. E, de volta, ele a torna experiência daqueles que ouvem a sua história. Assim, a escuta das narrativas pode dar um ritmo à vida. Trata-se dos suportes materiais da memória. Tempo de lembrar a substância social da memória, tendo os sujeitos como personagens das histórias contadas por eles mesmos, e nós como narradoras dessas experiências (BENJAMIN, 2012).

A narrativa constitui-se fundamentalmente em partilhar experiências vividas, impulsionadas por memórias. "Ela não está interessada em transmitir o 'puro em si' da coisa narrada, como uma informação ou um relatório. Ela mergulha a coisa na vida do narrador para em seguida retirá-la dele" (BENJAMIN, 2012, p. 221). É plausível, portanto, experimentar outros jeitos de pensar, fazer e sentir aquilo que nos aconteceu, nos conectando em outro tempo, e passado, presente e futuro são afetados nos impulsionando a produzir novos sentidos.

Revista Digital do LAV - Santa Maria - vol. 11, n. 1, p. 211 -234 - jan./abr. 2018 ISSN 1983 - 7348 http://dx.doi.org/10.5902/1983734830932 
Entretanto, a sustentação em que a memória se apoiava em tempos antigos hoje não há mais, pois as casas mudaram de cor, os lugares mudaram, as pessoas se mudaram, saíram de seus antigos lares, as árvores foram cortadas, as músicas não são mais tocadas. Tudo isso e muito mais está guardado na memória como paisagens de cada idoso (BOSI, 1979).

Nesse contexto, a reconstrução e a interpretação do passado significam um fazer valer o passado para o presente, o converter o passado num acontecimento do presente. Assim acontece a experiência.

A experiência do passado, portanto, não é um passatempo, um mecanismo de evasão do mundo real e do eu real. E não se reduz, tampouco, a um meio para adquirir conhecimentos sobre o que aconteceu ou o acontecido. "A interpretação do passado só é experiência quando tomamos o passado como algo ao qual devemos atribuir um sentido em relação a nós mesmos" (LARROSA, 2015, p. 135).

Podemos dizer que a experiência é o que nos acontece. Assim, num acontecimento em comum, ou entre duas pessoas, a experiência para cada uma delas será singular. Nesse sentido, Larrosa (2015, p. 32) discorre:

[...] se a experiência não é o que acontece, duas pessoas, ainda que enfrentem o mesmo acontecimento, não fazem a mesma experiência. O acontecimento é comum, mas a experiência é para cada qual sua, singular e de alguma maneira impossível de ser repetida.

E falando de experiência, de memória e das sensibilidades dos idosos/sujeitos, chegamos ao momento de compartilhar a escrita do processo de pesquisa nos dois territórios: CRAS e Centro de Artes.

\section{O campo de pesquisa - uma experiência singular}

A pesquisa de campo foi realizada com diversas ações mediadoras. Nossos sujeitos foram 30 idosos frequentadores do CRAS. Eles participaram ativamente das práticas educativas em musicalização e apreciação musical em espaços distintos: visita/expedição a um Centro de Artes e três oficinas de musicalização no CRAS.

Os idosos aqui apresentados são atendidos semanalmente no CRAS com atividades diversas, entre elas artes visuais, artesanato e atendimento da assistente social mantido pela Prefeitura. A idade dos idosos participantes da pesquisa foi estimada entre 60 e 85 anos.

Revista Digital do LAV - Santa Maria - vol. 11, n. 1, p. 211 -234 - jan./abr. 2018 ISSN 1983 - 7348 http://dx.doi.org/10.5902/1983734830932 
Numa primeira visita ao CRAS pudemos conhecer todos os senhores e senhoras que participariam do processo de investigação. Podemos dizer que para nós foi um momento ímpar, pois ali se iniciou um vínculo afetivo, que faria toda a diferença no decorrer da pesquisa. Durante essa visita descobrimos que alguns dos idosos nunca haviam ouvido música ao vivo, somente pelo rádio, pela televisão e nos bailes.

\section{Visita/expedição ao Centro de Artes}

A visita/expedição a um Centro de Artes foi nossa primeira ação de prática educativa em campo de investigação. O termo "visita/expedição" tem o significado como uma viagem de exploração a um lugar distante, em grupo - uma viagem com fins científicos, em que traz em si mesma as manifestações sensoriais e ainda as significações destas (GRANJA, 2006).

O intuito da visita/expedição foi sensibilizar os idosos por meio de uma apreciação musical. Nesse processo, também é possível desvelar a percepção, de suma importância para a construção humana. É por meio dela que conhecemos o mundo, os objetos e os fenômenos. A percepção agrega vários sentidos, como enxergar, ouvir, tocar, saborear, conhecer... A percepção humana "é dirigida pelo sujeito, orientada segundo um projeto, uma intencionalidade. O homem é capaz de orientar e desenvolver a sua própria aprendizagem perceptiva" (GRANJA, 2006, p. 53). E esse olhar tem enfoque no aguçar, apreciar, cativar, atrair, buscar o ser humano (o idoso) no mais profundo do seu ser, podendo expressar os seus sentimentos, emoções e sensações.

$O$ perceber e o conceber podem se articular, o ver e o ouvir podem se promulgar simultaneamente na percepção musical, numa expectativa multissensorial ou comunicação entre os sentidos. Nas palavras de Granja (2006, p. 56), "[...] ouvir não significa apenas registrar o audível, mas instaurar um estado de escuta que permita perceber a presença do audível e do visível virtualmente presentes".

Nessa relação de comunicação, de sentidos, de escuta e de visual, optamos pela exploração musical afetiva para os idosos, para que pudessem ouvir as músicas apresentadas, mobilizando a memória e os sentidos. Copland (2014, p. 25) menciona essa apreciação como "plano sensível", em que "[...] a maneira mais simples de ouvir música é entregar-se ao próprio prazer do som". Nesse sentido, podemos dizer que os idosos se entregaram ao prazer do som no ambiente daquele lugar repleto de arte, de pessoas, de artistas, de tantas sensibilidades. 
Iniciamos nossa exploração científica levando os idosos ao Centro de Artes. Ao chegar a esse espaço cultural, surpreendemo-nos com as falas de alguns idosos, os quais desconheciam tais lugares.

- Nunca estive numa escola de música antes, dizia um dos senhores.

- O que será que vamos encontrar lá dentro?, outro questionava!

Foi com imenso encantamento que os idosos adentraram no Centro de Artes. Logo na entrada todos os idosos se dirigiram ao auditório da escola. Nesse momento observamos a fisionomia de cada um deles, a surpresa e a novidade em estar num espaço de artes, de ver e de poder tocar nos objetos, nos instrumentos e conversar, sorrir e usufruir aquele tempo e lugar.

E outras conversas chegavam aos nossos ouvidos:

- Puxa, nunca tinha visto instrumentos musicais assim, ao vivo, confessou um dos idosos.

- Estou comovida, como esse lugar é grande!, falava outra idosa.

- No palco tem um piano que parece ser de novela!, comentava uma senhora para outra, quase cochichando.

E assim, fomos nos acomodando no espaço do auditório com as cortinas ainda fechadas no palco.

Preparamos o lugar em conjunto com os professores do Centro de Artes para a apresentação do 'Espetáculo Cênico-Musical Sou Porque Somos'. Às 10 horas a cortina do palco foi aberta e iniciou-se o espetáculo com a peça 'O amanhecer', de Edward Grieg (1843-1907), tocada ao piano para uma bailarina dançar... Foi um momento leve e ao mesmo tempo intenso.

Em seguida, o Quinteto de Dulcistas ${ }^{5}$ subiu ao palco tocando 'Danças Renascentistas', de Claude Gervaise (1525-1583), com sons suaves, dançantes, envolventes e elaborados. Seguido por um duo de violões à melodia de 'Cora Coração', de Stênio Marcius (compositor brasileiro), surpreendendo os ouvintes. Nesse instante percebemos haver uma conversa de olhares, de pensamentos, uma fala entre ouvintes, músicas e intérpretes. Aqui não podemos deixar de abordar Copland (2014,

${ }^{5}$ Dulcistas - pessoas que tocam flauta doce.

Revista Digital do LAV - Santa Maria - vol. 11, n. 1, p. 211 -234 - jan./abr. 2018 ISSN 1983 - 7348 http://dx.doi.org/10.5902/1983734830932 
p. 11), ao dizer: "[...] a audição inteligente, na qual o ouvinte deixa de ser um elemento passivo para tornar-se alguém que aceita com a música algum diálogo".

A peça 'Marcha Turca', de Wolfgang Amadeus Mozart (1756-1791), foi interpretada pelas pianistas/professoras Hilda e Gricelda ao piano em estilo de quatro mãos ${ }^{6}$. 0 impacto para os idosos foi o virtuosismo que a peça apresentava. As músicas 'Assum Preto', de Luiz Gonzaga (1912-1989), e 'Água de Beber', de Tom Jobim (1927-1994) e Vinicius de Moraes (1912-1980), foram interpretadas pela banda de professores e cantores.

Entretanto o samba 'Tiro ao Álvaro', de Adoniran Barbosa (1910-1982), foi a apresentação mais aplaudida pelos idosos, com banda, vozes e ainda um casal de dançarinos/professores com figurino dos anos 1940. Ficamos a imaginar que memórias múltiplas naquele momento se instauraram na mente daqueles senhores e senhoras! O ritmo do samba está muito próximo de nossa imaginação, ao movimento físico, então podemos associar a ideia da melodia desse ritmo a uma emoção íntima. Nas palavras de Copland (2014, p. 49),

O efeito causado na nossa sensibilidade por esses dois elementos primários [ritmo e melodia] é igualmente misterioso. Que uma boa melodia tenha o poder de nos comover é algo que até agora nenhuma análise foi capaz de explicar.

Seguimos com a audição, ativando sensibilidades. Na continuação dessa cartografia multisonora, os alunos do curso técnico em canto apresentaram 'Happy', de Pharrel Williams (1973), e 'Assim Caminha a Humanidade', de Lulu Santos (1953). Para finalizar, tocamos um medley ${ }^{7}$ dos anos 1980 , que foi muito divertido e apreciado por todos.

Para encerrar as apresentações da manhã, cantamos 'Baba Yetu', de Christopher Tin (1976), interpretada em dialeto africano, com a participação de todos os professores e alunos que naquele lugar se encontravam.

Os sons das palmas eclodiram novamente daquelas mãos que um dia já foram jovens, e a cortina se fechou. Tudo ficou em silêncio novamente, numa grande expectativa do que viria em seguida...

\footnotetext{
${ }^{6}$ Duas pessoas podem interpretar uma peça escrita para piano. Essa técnica é chamada de piano a quatro mãos.

7 Medley é um formato musical em que se incluem trechos de diversas músicas sem interromper nenhuma quando é cantada ou tocada. Nesse caso foram várias músicas dos anos 1980.
}

Revista Digital do LAV - Santa Maria - vol. 11, n. 1, p. 211 -234 - jan./abr. 2018 ISSN 1983 - 7348 http://dx.doi.org/10.5902/1983734830932 
Após a apreciação musical, o grupo de idosos foi convidado a conhecer o espaço do Centro de Artes, as salas de aulas de música, de artes, de fotografia, de dança, de musicalização, bem como a exposição de artes dos alunos do curso de desenho, no primeiro andar da escola. Além de todas as novidades desse território que nunca haviam habitado, alcançamos algo a mais, um espetáculo ao vivo para o grupo de idosos. Isso se traduziu não somente nos sorrisos, nos olhares, como também nas falas de alguns deles:

- Que lindo, ver um espetáculo ao vivo, pois eu só tinha visto na televisão, disse um dos idosos.

Aqui destacamos a cartografia como abordagem metodológica de pesquisa que nos propiciou ir por caminhos diferentes quando o movimento se alterava. Alvarez e Passos (2014, p. 131) ressaltam que "cartografar é habitar um território existencial". O cartógrafo encontra-se imerso no território não visível e, ao mesmo tempo, atento aos signos que estão ao seu entorno. Nosso engajamento, como pesquisadores, acontece num compartilhar de um território existencial em que sujeito e objeto se relacionam.

Nesse sentido, pesquisar com alguém ou com algo e com engajamento, e não sobre algo, é o objetivo. Ocupamos um lugar de pesquisador, observador, abertos ao que aconteceria na experiência. E fomos acompanhando, aprendendo com os idosos, nas suas singularidades e no grande coletivo que se formou. Estávamos todos atentos naquele território.

E com alguns comentários e expressões não faladas, conduzimos o grupo para uma das salas, a fim de realizar uma roda de conversa. Cada um deles revisitou suas memórias a partir das suas experiências com a audição do espetáculo. Uns se lembraram das músicas que dançavam em bailes, onde alguns conheceram o seu grande amor na juventude; outros recordaram das festas sempre movidas com muita música, dança e comida; alguns ainda relembraram as letras e canções preferidas e que jamais ficaram esquecidas em seu coração e na memória.

Muitos deles recordaram e falaram do respeito e do compromisso que no "tempo deles" existia, como as juras de amor, a sinceridade do carinho demonstrado uns pelos outros, entre os amigos ou entre a namorada e o namorado. Nesse momento, alguns dos idosos fizeram um breve comparativo entre o passado e o presente, dizendo que hoje falta respeito no amor, faltam fraternidade, compreensão... "Tudo 
é passageiro... As pessoas estão se perdendo... Não há mais tempo para conversar e amar", desabafou uma das idosas. E nas palavras de Alves (2010, p. 155):

O amor na velhice é um espanto, pois nos revela que o coração não envelhece jamais. Pode até morrer, mas morre jovem. [...] O amor tem o poder mágico de fazer o tempo correr ao contrário. O que envelhece não é o tempo. É a rotina, o enfado, a incapacidade de se comover ante o sorriso de uma mulher ou de um homem. Mas será incapacidade mesmo?

Alves (2010) alerta-nos de que o amor transcende o tempo e que vai se transformando em outros amores: da companheira ou do companheiro, dos filhos, dos netos e de outros tantos amores que vão surgindo. A memória foi ativada pela ação musical, e nesse contar histórias vivas e vividas, aquela roda de conversa ficava cada vez mais interessante, desvelando segredos guardados, que só então foram revelados. Um dos idosos comentou: Quando festejávamos um aniversário de algum dos amigos, todos eram surpreendidos com tiros ao alto, na frente de suas casas. Esse era sempre um motivo para se ouvir muitas músicas, dançar, beber e comer. E continuou: Era morto um porco, galinhas, dando muitas risadas e se divertindo muito.

Ainda naquela manhã, ouvindo histórias de vida, descobrimos algo surpreendente: um dos idosos compartilhou conosco que fora músico e que outrora fizera parte da dupla sertaneja Zé Tapera e Teodoro, de 1965 a 1980. Uma carreira de sucesso por 15 anos, com muitas composições criadas a partir dos seus amores não correspondidos, dos bons momentos alegres e outros tristes que o cercaram durante esse tempo de shows em sua carreira.

Disse ele: "Entre tantos desamores, o maior deles foi ter deixado partir minha amada para ser feliz com outro homem, e de estar sozinho até hoje". Um senhor com saúde frágil, acometido num leito aos cuidados de sua irmã e que tem em suas memórias um consolo em seus dias atuais e a esperança de voltar a encontrar o amor de sua vida, mesmo que por alguns instantes... Outras memórias vieram de outros idosos que narravam sobre sua infância, sua terra natal, seus pais, filhos e amigos.

A música foi o que mais chamou a atenção daqueles senhores e senhoras da terceira idade, pois é também linguagem e expressão, constituída de (sons) palavras não ditas, frases não relatadas, períodos não comentados. No entanto os ritmos outrora fragmentados pelo pulso constante da música estão nas figuras de notas musicais e na melodia com frases repetidas.

Revista Digital do LAV - Santa Maria - vol. 11, n. 1, p. 211 -234 - jan./abr. 2018 ISSN 1983 - 7348 http://dx.doi.org/10.5902/1983734830932 
Além de cumprir um papel social como proposta de acesso à cultura e de formação de plateia, ativamos muitos outros sentidos no grupo de idosos nesse dia de visita/expedição. Não houve apenas uma apreciação musical afetiva; transportamonos num bloco de sensações, e estas envolvidas de muita leveza, suavidade, nostalgia, alegria e, ao mesmo tempo, de muitos afetamentos com significados distintos a cada sujeito ali presente.

A terceira idade parece estar surgindo como uma possibilidade de se pensar uma nova maneira de ser idoso, apresentando outros modos de olhar a vida. Em vez de ficarem em casa, isolados, podem buscar outros prazeres: encontros com amigos, bailes, viagens, visita a espaços culturais, como museus, teatros, universidade abertas à terceira idade, escolas para visita/expedições, entre tantos outros. Lima (2000, p. 23) discorre:

O movimento da Terceira Idade emerge com uma força ainda desconhecida por aqueles que a vivenciam, de sujeitos que tornam visível a possibilidade de modificação da velhice, tirando os rótulos e contestando os mitos.

Ao pensar sobre o ritmo da vida dos idosos participantes da presente pesquisa, percebemos que, tratando-se de terceira idade, o ritmo de cada idoso difere de acordo com seu entendimento de vida. Essa concepção de fragilidade ou limitação não é o mesmo pensamento de todos dessa etapa de vida.

Aprender não é apenas uma questão ou um direito de uma só idade, pois nós, humanos, estamos em constante formação. O pensamento de que o idoso, ao se aposentar da vida profissional, deva ficar ocioso, acomodado já não faz parte da 'nova geração' da terceira idade. Esse idoso é mais atuante, participativo de atividades culturais, de práticas acessíveis e relacionadas à sua cultura. Encontrar atividades e práticas que Ihe interessem, que sejam significativas, seja qual for o seu nível cultural ou classe social, é ainda um desafio, entretanto pesquisas estão caminhando nesse aspecto para impulsionar tal dinâmica social (BRANDÃO; SILVA; REBELO, 2003).

\section{Práticas educativas em musicalização - oficinas no CRAS}

Propusemos três oficinas aos idosos, constituídas em encontros com a música, por meio das vivências, experiências e audições. Depois de pensadas, planejadas e organizadas, foram realizadas, e nesse processo, percebemos que o grupo esteve aberto a conhecer novidades no que se refere às artes e em especial a música. Os

Revista Digital do LAV - Santa Maria - vol. 11, n. 1, p. 211 -234 - jan./abr. 2018 ISSN 1983 - 7348 http://dx.doi.org/10.5902/1983734830932 
idosos foram provocados a revisitar suas memórias musicais, e nesse movimento histórias foram desveladas, relembradas, coletadas e acolhidas por nós.

A educação como prática educativa em musicalização na terceira idade representa um dos caminhos para serem explorados e percorridos. Com tais ações em musicalização, percebemos que a experiência pôde contribuir de forma significativa com esse grupo de idosos, e principalmente conosco, ao redescobrirmos nossas próprias memórias. As relações de interatividade entre o grupo e o grupo conosco tiveram os vínculos afetivos como o maior aliado no processo, reiterados pelas palavras de Penna (2015, p. 31):

[...] a compreensão da música, ou mesmo a sensibilidade a ela, tem por base um padrão culturalmente compartilhado para a organização dos sons numa linguagem artística, padrão este que, socialmente construído, é socialmente apreendido pela vivência, pelo contato cotidiano, pela familiarização [...].

Assim, pensamos que a afetividade na relação com os idosos durante o processo da visita/expedição, tanto das oficinas de musicalização quanto das entrevistas feitas, provocou o pensar/fazer/experienciar musical, entrelaçando afetos.

Foi um processo de produção de subjetividades nas observações, nas práticas, nas conversas, e com os diversos efeitos com os idosos e conosco, como é proposto pela abordagem cartográfica. Nesse viés, encontramos a narrativa que se apresenta nas vozes dos partícipes durante as oficinas de musicalização com os idosos.

Uma das idosas narrou, durante as práticas educativas em musicalização, que no seu tempo de juventude ouvia muita música pelo rádio e na igreja. Percebemos, desde o início do convívio com ela, que gostava muito de cantar e que as músicas ouvidas e apreciadas em seu cotidiano construíram esse gosto musical. Ela nos contou que seu avô era músico e que era ele quem tocava e animava as festas de casamentos, dos bailes e das rodas de conversa. Disse ainda que desde criança o observava tocando e acompanhando a banda. Não era um profissional, mas tocava junto com seus tios e sua mãe.

Essa senhora já nasceu no meio musical, pois sua mãe lhe contava que, desde que ela aprendeu a falar, ao mesmo tempo cantava. E cantava o tempo todo, esbanjando alegria em casa e na igreja. Mais tarde, ela foi designada para escolher os cantos da liturgia, o que the deixou muito orgulhosa, dizendo que o seu meio cultural a influenciou a gostar de ouvir música e cantar. Na escola conheceu um professor que

Revista Digital do LAV - Santa Maria - vol. 11, n. 1, p. 211 -234 - jan./abr. 2018 ISSN 1983 - 7348 http://dx.doi.org/10.5902/1983734830932 
tocava violão, identificou-se com ele e juntos tocavam e cantavam para os demais alunos da sala. Nesse período, o encantamento pela música foi potencializado, e mobilizada pelo professor e pelo amor à música, começou algo que the dava muito prazer - compor letras e melodias para algumas canções.

E nesse contexto de falas, palavras, letras musicadas e sensíveis aos momentos e territórios, a pesquisa torna a enlaçar-se com o prazer, o lúdico, a sedução, a aventura, o segredo e se compreende em uma dimensão mais holística. A pesquisa narrativo-artística aparece nesse movimento em uma dimensão intensa dos estudos, transportando-os para outros processos de estudos que unem em harmonia a prática, a teoria, o olhar sensível e a razão. Propõe pistas alternativas de indagar, e compreende-se o método como caminho que nos convida à deriva do descobrimento do que nos rodeia neste mundo.

\section{Últimas considerações}

Aqui descrevemos nossa percepção, dando voz aos efeitos e aos afetamentos que foram provocados pelas práticas educativas envolvendo a musicalização com idosos, tendo como referência a ação mediadora e a sensibilidade, mobilizando memórias e experiências como possibilidade de construção de sentidos e relações com o cotidiano. Dar voz a esses afetos foi a nossa maior preocupação enquanto pesquisadoras/cartógrafas.

Por meio da experiência é possível, como dizem Deleuze e Guattari (2012a), improvisar continuamente novos modos de existência. Os autores nos provocam quando afirmam que é preciso fazer rizoma e não raiz! "Não semeiem, piquem. Façam linhas e nunca pontos. Vão, façam! " (DELEUZE; GUATTARI, 2012a, p. 48). Talvez os autores dissessem: vão, experimentem, experienciem... Afetem-se, aprendam... Afetem-se, descubram... Afetem-se, vivam. Esse é um caminho?

A prática educativa em musicalização propôs provocar o desejo de participar, de experimentar, de ser contaminado, de estar envolvido - incorporado. As práticas propuseram de certa forma sair de uma condição estável para uma condição, a priori, desconfortável, tanto física quanto afetiva e intelectiva. Talvez seja por isso que ouvimos tantos 'Eu nunca vi isso', 'Eu nunca fiz isso', 'Eu nunca pensei nisso' e 'Eu nunca senti isso'. Será que os sentidos estavam adormecidos? 
Provocamo-nos envolvendo a música, os aromas, e também o contato, a atenção, o carinho.... Buscamos o que Deleuze e Guattari (2012a) chamam de desterritorialização.

Usamos do método da cartografia para perceber o ritmo (e nunca a medida) de como acontecem os processos pelos quais os idosos estão imersos em seu cotidiano, como e quais são esses passados que estão inscritos em seus corpos e suas memórias.

A musicalização fez-se necessária como ativadora e plano de flutuação para que conexões pudessem ser estabelecidas. Logo percebemos a fragilidade de um passado por tempos esquecidos e um presente-passado, algo que escapava constantemente pelo desgaste natural do corpo no tempo (idade avançava). Algo que teimava em nos confundir.

Nas práticas educativas em musicalização os idosos foram convidados a participar das experiências musicais, cantando, tocando instrumentos de percussão, ativando a memória de canções e histórias de vida. É nesse sentido que a pesquisa propôs sair de uma condição estável para uma situação, a priori, desconfortável. O que não significa que foi algo ruim, pelo contrário. Percebemos nos idosos que, ao se expor em grupo, ao ativar o pensamento, ao buscar as memórias, ao escutar o outro, algo de saudável, de verdadeiro nos atravessava ou simplesmente pairava no ar.

Analisar as práticas educativas em musicalização na terceira idade, mobilizando memórias e experiências como construção de sentidos e relações com o cotidiano foi um dos nossos desafios. E podemos dizer que essas práticas contribuíram para que os idosos percebessem que passado e presente estão articulados em novos sentidos, ou seja (re)significados. Revisitar memórias não se resume apenas em um pensamento nostálgico. Diz muito mais de quem somos e como nos constituímos a partir do que fomos e do que podemos vir a ser. Essa foi sem dúvida uma constatação que valorizou as memórias dos idosos e principalmente os fez dar maior sentido as suas vidas cotidianas e seus novos percursos de vida e de desterritorialização.

E como avaliar esses processos de desterritorialização também é nossa função de cartógrafas e percebemos que a improvisação, ou simplesmente a ação de se permitir fazer, foi um desses processos que se destacou.

Revista Digital do LAV - Santa Maria - vol. 11, n. 1, p. 211 -234 - jan./abr. 2018 ISSN 1983 - 7348 http://dx.doi.org/10.5902/1983734830932 
Entendemos que a improvisação não é uma prática contínua ou comum para os idosos, estamos acostumados com os jovens se arriscarem em coisas novas ou coisas diferentes. Propor a um grupo de pessoas a possibilidade de recriar, de mergulhar, de tentar (errar ou acertar), de desvendar os mistérios de sua própria memória foi o risco que escolhemos. Optamos pelo caminho/movimento da improvisação.

Nesta pesquisa optamos pelo conceito de improvisação não no sentido de despreparo, mas sim pelo fato de acreditarmos que o idoso tem muito a nos ensinar. Os idosos possuem muitas experiências, muitas referências, muitos afetamentos e muitas vivências desta e de outras épocas. Épocas que não voltam mais; cabe-nos apenas reconstruir.

Logo, a improvisação também dialoga com Deleuze e Guattari (2012a) quando dizem que estamos sempre em territórios de sentidos. As coisas acontecem, dançamos num ritmo sempre diferente, nunca estável por completo. De tempos em tempos, conforme vivemos, estabelecemos ou criamos sentidos diferentes para as mesmas coisas. Assim, o mesmo não é mais o mesmo. Estamos, inevitavelmente, criando sempre outros territórios de sentidos para a vida, o viver.

A prática educativa em musicalização consistiu no aprendizado e na troca de experiências com os idosos, incentivando a serem criativos e reinventando seu cotidiano. Os idosos foram provocados a imergir em um universo sonoro/musical e descobrirem ora juntos, ora solitários suas próprias potencialidades e prazeres. Por vezes o movimento corporal fora despertado, por vezes o canto, por vezes a memória, ao lembrarem uma música preferida ou de momentos do passado, adormecido pelas circunstâncias da vida.

A prática educativa em musicalização também contribuiu nas ações de socialização, uma vez que possibilitou experiências em que os sentidos, as relações afetivas e as memórias dos idosos pudessem ser ressignificados. A mediação pela musicalização possibilitou saberes e contribuiu na desconstrução de alguns conceitos: que o idoso já aprendeu tudo na vida ou que não pode mais viver com prazer. Quer dizer, permitiu a construção de outros sentidos ao tempo da terceira idade.

A pesquisa provocou-nos a refletir sobre os caminhos/linhas ou alternativas que a musicalização, a partir das histórias narradas e musicadas, pode nos provocar, além de introduzir-nos novamente na aventura do conhecimento... Tramas e linhas do tempo constituídas de experiências, de vivências, de modos de viver sempre estão 
sugerindo processos de busca. Buscas pelo conhecimento, buscas pelo amor, e buscas pelo desejo.

Percebemos que as narrativas dos idosos nos remeteram a manifestações artísticas culturais. As escolhas pelas músicas, e como aconteceram, revelaram um potencial que amplifica as pistas de pesquisa e nos reintegra em uma reflexão coletiva (MARTINS; TOURINHO; SOUZA, 2017).

Aprendemos com os idosos que a vida precisa ter sentido e ser ressignificada em cada movimento/ritmo. Percebemos com os idosos que a vida não precisa ser totalmente contagiante, a todo o momento, mas que a vida precisa ter momentos de êxtase, momentos que despertem a sensibilidade e que sejam impossíveis de se esquecer. Descobrimos que é importante ter histórias para contar, e que é importante ter a quem contar.

Em especial a pesquisa com os idosos contribuiu, a partir da musicalização, para reativar memórias, trazendo recordações das músicas e letras de vários momentos de suas vidas, articulando passado/presente. A vivência com os instrumentos, a socialização no CRAS, a visita/expedição a um Centro de Artes e a apreciação musical, além do compartilhamento entre o grupo de ideias e sentires, contribuiu para ampliar repertórios e compreender a música como propulsora de sentimentos e prazer. A apreciação musical alimenta a nossa alma, nos provocando a descobrir coisas em nós que ainda não conhecemos. As memórias, histórias do cotidiano que marcaram as vidas dos idosos, de alguma forma foram mobilizadas pela apreciação musical.

Experiências inquietantes configuraram percepções de um cotidiano marcado pela longa estrada da vida. Experiências inquietantes levam-nos à autorreflexão, deslocando afetos, vestígios e lembranças de um lugar para outro, apontando "[...] um caminho biográfico-narrativo de entendimento da vida, considerando para isso os aspectos subjetivos presentes em cada imagem e episódio" (MARTINS, TOURINHO, SOUZA, 2017, p. 344).

Na construção desta pesquisa pudemos observar que nada está concluído e que o tema musicalização, mobilizando memórias, experiências e sensibilidades na terceira idade, pode gerar muitas outras pesquisas e questionamentos. No mapa que construímos ao longo do processo de musicalização com idosos observamos que nada é estável no sentido de estabelecer verdades absolutas, principalmente quando 
falamos da vida e dos sentidos que atribuímos às coisas do mundo. Nas palavras de Deleuze e Guattari (2012a, p. 30), "o mapa é aberto, é conectável em todas as suas dimensões, desmontável, reversível, suscetível de receber modificações constantemente". A pesquisa escapa e desdobra-se em outras investigações, que demandam outros sujeitos e outras histórias. Nesse sentido, esta pesquisa poderá ser conectável a muitas outras e contribuir em outras áreas que estejam construindo seus próprios mapas de sentidos.

O por que? Fazer e apreciar música oportunizou o compartilhamento de ideias e sentires.

\section{Referências}

ALVAREZ, J.; PASSOS, E. Cartografar é habitar um território existencial. In: PASSOS, E.; KASTRUP, V.; ESCÓSSIA, L. da (Orgs.). Pistas do método da cartografia: pesquisa-intervenção e produção de subjetividade. 2 v. Porto Alegre: Sulina, 2014.

ALVES, R. Do universo à jabuticaba. São Paulo: Planeta do Brasil, 2010.

. Educação dos sentidos e mais... 9. ed. Campinas: Verus, 2012.

Pimentas: para provocar um incêndio, não é preciso fogo... 2. ed. São Paulo: Planeta, 2014.

BENJAMIN, Walter. Magia e técnica, arte e política: ensaios sobre literatura e história da cultura. Tradução de Sérgio Paulo Rouanet. 8. ed. rev. São Paulo: Brasiliense, 2012 (Obras escolhidas, v. 1).

BOSI, E. Memória e sociedade: lembrança de velhos. São Paulo: T. A. Queiroz, 1979.

BRANDÃO, J. da S.; SILVA, M. D. da; REBELO, R. A. A vida na maturidade: uma contribuição à educação permanente. Blumenau: Nova Letra, 2003.

COPLAND, A. Como ouvir e entender música. Tradução de Luiz Paulo Horta. 2. imp. São Paulo: Realizações, 2014.

CRAS - CENTRO DE REFERÊNCIA DE ASSISTÊNCIA SOCIAL. Disponível em: <https://www.joinville.sc.gov.br/departamento/sas/centros-de-referencia-emassistencia-social-cras/\#competencia>. Acesso em: 19 abr. 2017.

DELEUZE, G.; GUATTARI, F. Mil platôs: capitalismo e esquizofrenia. Tradução de Ana Lúcia de Oliveira, Aurélio Guerra Neto e Célia Pinto Costa. 2. ed. 1 v. São Paulo: 34, 2012a. (Coleção TRANS).

Mil platôs: capitalismo e esquizofrenia. Tradução de Suely Rolnik. 2. ed. 4 v. São Paulo: 34, 2012b. (Coleção TRANS).

O que é filosofia? Tradução de Bento Prado Jr. e Alberto A. Muñoz. 3. ed. São Paulo: 34, 2010.

Revista Digital do LAV - Santa Maria - vol. 11, n. 1, p. 211 -234 - jan./abr. 2018 ISSN 1983 - 7348 http://dx.doi.org/10.5902/1983734830932 
DICIONÁRIO Grove de música. Edição concisa/editado por Stanley Sadie. Tradução de Eduardo F. Alves. Rio de Janeiro: Jorge Zahar, 1994.

DUARTE JR., J. F. O sentido dos sentidos: a educação (do) sensível. 5. ed. Curitiba: Criar, 2010.

GRANJA, C. E. de S. C. Musicalizando a escola: música, conhecimento e educação. São Paulo: Escrituras, 2006.

KASTRUP, V.; BARROS, R. B. de. Movimentos-funções do dispositivo na prática da cartografia. In: PASSOS, E.; KASTRUP, V.; ESCÓSSIA, L. da (Orgs.). Pistas do método da cartografia: pesquisa-intervenção e produção de subjetividade. Porto Alegre: Sulina, 2014. 2 v.

LARROSA, J. Notas sobre a experiência e o saber de experiência. Revista Brasileira de Educação, n. 19, p. 20-28, jan. /abr. 2002.

Tremores: escritos sobre experiência. Tradução de Cristina Antunes e João Wanderley Geraldi. Belo Horizonte: Autêntica, 2015. (Educação: experiência e sentido).

LIMA, M. P. Gerontologia educacional: uma pedagogia específica para o idoso: uma nova concepção de velhice. São Paulo: LTr, 2000.

LUZ, M. C. Educação musical na maturidade. São Paulo: Som, 2008.

MARTINS, R.; TOURINHO, I.; SOUZA, E. C. de (Orgs.). Pesquisa narrativa: interfaces entre histórias de vida, arte e educação. Santa Maria: Editora UFSM, 2017.

MEIRA, M.; PILLOTTO, S. S. D. Arte, afeto e educação: a sensibilidade na ação pedagógica. Porto Alegre: Mediação, 2010.

PASSOS, E.; BARROS, R. B. de. A cartografia como método de pesquisa-intervenção. In: _ ; KASTRUP, V.; ESCÓSSIA, L. da (Orgs.). Pistas do método da cartografia: pesquisa-intervenção e produção de subjetividade. Porto Alegre: Sulina, 2014. 2 v.

PENNA, M. Música (s) e seu ensino. 2. ed. Porto Alegre: Sulina, 2015.

SOUZA, Jusamara (Org.). Aprender e ensinar música no cotidiano. Porto Alegre: Sulina, 2008.

SUÁREZ, D. H. Prefácio. In: MARTINS, R.; TOURINHO, I.; SOUZA, E. C. de (Orgs.). Pesquisa narrativa: interfaces entre histórias de vida, arte e educação. Santa Maria: Ed. da UFSM, 2017.

TORREGROSA, A. Da arte e da narração à sensível textura de nós. In: MARTINS, R.; TOURINHO, I.; SOUZA, E. C. de (Orgs.). Pesquisa narrativa: interfaces entre histórias de vida, arte e educação. Santa Maria: Ed. da UFSM, 2017.

\footnotetext{
' Mestranda em Educação pela Univille. Graduada em Letras pela Faculdade de Educação, Ciências e Letras de Cascavel (1986) e Especialista em Educação Musical pela Escola de Música e Belas Artesdo Paraná (2013). Atualmente é Professora do Conservaório Belas Artes de Joinville. Tem experiência na área de Artes, com ênfase em Música.

ii Pós-Doutora no Instituto Estudos da Criança - IEC na Universidade do MINHO - UMINHO, Braga/Portugal em 2007/2008. Doutora em Engenharia de Produção (Gestão da Qualidade) pela
} 
Universidade Federal de Santa Catarina - UFSC (2003); Mestre em Educação (Currículo) pela Universidade Federal do Paraná - UFPR (1997) Especialista em Fundamentos Estéticos para a Arte na Educação pela Faculdade de Artes do Paraná (1992); Graduada em Educação Artística Habilitação Artes Plásticas pela Universidade para o Desenvolvimento do Estado de Santa Catarina - UDESC (1983) Professora titular nos cursos de Artes Visuais e Pedagogia na Universidade da Região de Joinville - UNIVILLE e no Programa de Pós-Graduação - Mestrado em Educação; Pesquisadora e Coordenadora de Núcleo de Pesquisa em Arte na Educação - NUPAE, possui experiência nas áreas de Artes, Gestão, Currículo, Avaliação; Infância e Arte/Educação. Avaliadora do INEP, atua nos seguintes níveis da educação: educação superior e pós-graduação. Autora de vários livros publicados, desenvolve formação continuada e consultoria nas áreas citadas. iii

Mestra em Educação pela Universidade da Região de Joinville - UNIVILLE em Joinville/SC (2017). Especialista em Fundamentos do Ensino da Arte pela Faculdade de Artes do Paraná (2007). Graduada em Educação Artística - Habilitação Licenciatura em Música pela Faculdade de Artes do Paraná em Curitiba/PR (2004). Graduada Plena em Pedagogia pelo Centro Universitário Leonardo DA Vinci SC (2010). Professora dos Cursos Técnicos de Música e Diretora Pedagógica do Conservatório Belas Artes de Joinville. Professora seminarista e coordenadora da Região Sul do Brasil do Programa Sopro Novo - Musicalização através da Flauta Doce da Yamaha Musical do Brasil. Pesquisadora do Núcleo de Pesquisa em Arte na Educação - NUPAE - Universidade da Região de Joinville - UNIVILLE/ Joinville/SC.

Como citar esse artigo:

NATUME, Hilda; PILLOTO, Silva Sell Duarte; STRAPAZZON, Mirtes Antunes Locatelli. Musicalização: memórias, experiências e sensibilidades na terceira idade. Revista Digital do LAV, Santa Maria: UFSM, v. 11, n. 1, p. 211-234, jan./abr. 2018.

Enviado em: 23 de janeiro de 2018

Aprovado em: 22 de março de 2018. 